\title{
Associations between Living Alone and Smoking and Alcohol Consumption in Korean Adults
}

\author{
Sang-Woo Lee', Byoungduck Han', Sung Jung Cho', Seung Jin Jung', Youn Huh², Junghun Kim', Do Hyun Eum', \\ Taeryoon Kim', Soon-Hong Min', Woohyun Lee', Jinhee Cho', Min Hee Kwon', Ga Eun Nam ${ }^{13, *}$ \\ 'Department of Family Medicine, Sahmyook Medical Center, Seoul, Korea \\ ${ }^{2}$ Department of Family Medicine, Inje University Ilsan Paik Hospital, Inje University College of Medicine, Goyang, Korea \\ ${ }^{3}$ Department of Family Medicine, Korea University Anam Hospital, Korea University College of Medicine, Seoul, Korea
}

Background: Recently, single-person households have increased in Korea and this trend may have potential public health implications and affect various health behaviors. This study investigated the associations between living alone and health behaviors such as smoking and alcohol consumption among Korean adults.

Methods: We used data from the 6th Korea National Health and Nutrition Examination Survey between 2013 and 2015 and a total of 17,088 adults were included. We performed a multivariable logistic regression analysis and calculated odds ratios (ORs) with $95 \%$ confidence intervals (CIs).

Results: Single-person households accounted for about $10 \%$ of the total participants. The proportions of currently smoking and heavy alcohol consumption were higher among individuals living alone than those living together among younger women and middle-aged and elderly men and women. In the multivariable logistic regression analysis, living alone was associated with increased odds of currently smoking compared to living together among middle-aged men and women (OR, 7.37; 95\% CI, 2.33-23.32 in men and OR, 2.36; 95\% CI, 1.04-5.36 in women) after adjusting for confounding variables.

Conclusion: From this nationwide, population-based study, we found that living alone is associated with increased odds of currently smoking, especially in middle-aged people. Public health concerns may be warranted for middleaged single-person households to reduce health risks related to smoking.

Keywords: Single-Person Household; Living Alone; Health Behavior; Smoking; Alcohol Consumption; Korean Adults

Received: August 6, 2018, Revised: February 8, 2019, Accepted: March 3, 2019

*Corresponding Author: Ga Eun Nam https://orcid.org/0000-0002-6739-9904

Tel: +82-2-920-5104, Fax: +82-2-928-8083,E-mail: namgaaa@daum.net 


\section{INTRODUCTION}

Recently, single-person households have increased in all age groups all over the country similar to other industrialized countries. ${ }^{1,2)}$ Singleperson households have not only weaker economic status but also weaker psychophysical conditions. The time before which young people get married seems to be delayed because individualistic cultures weigh the pros and cons of marriage. This trend is more prevalent among individuals who have a higher educational degree. ${ }^{3,4)}$ In middle-aged groups, single-person households were reported at about $32.5 \%$ in $2016,{ }^{2)}$ and this seems to be mostly due to divorce. ${ }^{5)}$ Temporary workers and simple laborers largely comprise of middle-aged single-person households and this group tends to have an unstable income status. ${ }^{5)}$ Along with the society of nuclear families, there are a large number of elderly people living alone who do not want to depend on their children. ${ }^{5)}$

The World Health Organization has defined health as being not only the absence of disease and infirmity but also the presence of physical, mental, and social well-being. ${ }^{6}$ From this perspective, being in singleperson households may potentially affect various health behaviors. Moreover, deteriorated health behaviors are risk factors of many chronic diseases such as obesity, hypertension, diabetes mellitus (DM), metabolic syndromes, cardiovascular disease, and cancers.

A study of young Korean people reported that the odds ratio (OR) for currently smoking (6.19; 95\% confidence interval [CI], 2.17-17.7) and alcohol consumption (2.67; 95\% CI, 1.09-6.52) among women living alone is higher compared to those living together. However, there was no difference in these health behaviors between men living alone and those living together. ${ }^{7)}$ In a study of elderly people, odds of smoking was 1.8 times (95\% CI, 1.21-2.67) higher in men living alone than those living together, and 1.4 times (95\% CI, 1.03-1.92) higher in women living alone than those living together. ${ }^{8)}$ These results suggest that living alone may affect health behaviors differently according to age and sex groups.

Thus, we aimed to examine the association between single-person households and risky health behaviors such as currently smoking and heavy alcohol consumption among adults using nationally representative data of the South Korean population. We additionally performed subgroup analyses according to the combination of age and sex groups.

\section{METHODS}

\section{Study Population}

This population-based cross-sectional study was based on the data from the 6th Korea National Health and Nutrition Examination Survey (KNHANES) between 2013 and 2015. The KNHANES is designed to obtain national estimates of the health and nutritional status of South Koreans and has been conducted by the Korea Centers for Disease Control and Prevention (KCDC) since 1998. The survey consists of three parts: health interview, health examination, and nutrition sur- veys. Among 22,948 individuals in 9,491 households who participated in the 6th KNHANES 2013-2015, we excluded 5,860 individuals aged $<19$ years. Finally, data from 17,088 adults (7,322 men and 9,766 women) were analyzed. The KNHANES is approved by the institutional review board of the KCDC. All participants in KNHANES signed an informed consent form.

\section{Definition of Living Arrangement}

We classified participants into two groups, living alone and living together, based on responses to the items regarding the type of household.

\section{Assessment of Smoking Status and Alcohol Consumption}

Data regarding health behaviors including smoking status and alcohol consumption were obtained by self-administered questionnaires at a mobile medical testing center. Participants who had smoked at least 100 cigarettes in their lifetime and smoke every day or occasionally, were defined as current smokers. Participants who had smoked at least 100 cigarettes in their lifetime and currently do not smoke at all, were defined as ex-smokers. Never-smokers were defined as individuals who had never smoked or smoked less than 100 cigarettes in their lifetime at the time of the survey. Alcohol consumption was categorized into three groups based on the amount and frequency of alcohol intake. Alcohol intake of more than an average of seven drinks for men and five drinks for women at least twice a week, regardless of the kind of alcohol, was defined as heavy alcohol consumption.

\section{Covariates}

Past medical history including hypertension and DM was based on the diagnosis from a physician. Psychological stress was assessed using the question "Do you experience psychological stress in your daily life?" Thereafter, individuals who responded "yes" were defined as stress group. The question "Have you suffered from feelings of sadness or hopelessness for more than 2 weeks during the past year?" was included to inquire about depressive mood, and if individuals answered "yes," they were regarded as having a depressive mood. Participants' height and weight were measured, and the body mass index (BMI) was calculated as weight $(\mathrm{kg})$ divided by the square of the height $\left(\mathrm{m}^{2}\right)$.

\section{Statistical Analysis}

Data were expressed as mean \pm standard error (SE) for continuous variables or as percentages (SE) for categorical variables. We performed independent t-test or a chi-square test to compare participants' characteristics including smoking status and alcohol consumption according to living arrangement. We performed a multivariable logistic regression analysis and calculated the ORs with $95 \%$ CIs to evaluate the association of single-person households with currently smoking and heavy alcohol consumption after adjusting for age, sex, BMI, smoking status, alcohol consumption, income, educational level, occupation, psychological stress, depressive mood, hypertension, and DM. All statistical analyses were performed using the IBM SPSS Statistics ver. 21.0 
(IBM Corp., Armonk, NY, USA). Two-sided P-value of $<0.05$ was considered an indicator of statistical significance.

\section{RESULTS}

General characteristics of the study participants according to the groups, living alone and living together are depicted in Table 1. Approximately $10 \%$ of the total participants lived alone. Elderly people demonstrated the highest proportion $(39.9 \%)$ of living alone $(\mathrm{P}<0.001)$ and women had a higher proportion of living alone than men

Table 1. General characteristics of study participants according to living alone or living together

\begin{tabular}{|c|c|c|c|}
\hline Characteristic & Living alone & Living together & P-value* \\
\hline No. of participants & 1,704 & 15,384 & \\
\hline Mean age (y) & $55.2 \pm 1.1$ & $45.5 \pm 0.2$ & $<0.001$ \\
\hline Age range $(y)$ & & & $<0.001$ \\
\hline 19-39 & $27.2(2.5)$ & $38.5(0.6)$ & \\
\hline $40-64$ & $32.9(1.7)$ & $47.9(0.5)$ & \\
\hline$\geq 65$ & $39.9(2.0)$ & $13.6(0.4)$ & \\
\hline Sex & & & 0.001 \\
\hline Men & $43.9(1.8)$ & $50.0(0.4)$ & \\
\hline Women & $56.1(1.8)$ & $50.0(0.4)$ & \\
\hline Body mass index $\left(\mathrm{kg} / \mathrm{m}^{2}\right)$ & & & 0.15 \\
\hline$<18.5$ & $4.2(0.6)$ & $4.8(0.2)$ & \\
\hline $18.5-24.9$ & $60.5(1.5)$ & $62.8(0.5)$ & \\
\hline$\geq 25.0$ & $35.3(1.4)$ & $32.5(0.5)$ & \\
\hline Smoking status & & & 0.001 \\
\hline Non-smoker & $57.0(1.7)$ & $59.8(0.5)$ & \\
\hline Ex-smoker & $15.4(1.2)$ & $17.9(0.4)$ & \\
\hline Current smoker & $27.6(1.6)$ & $22.2(0.5)$ & \\
\hline Alcohol consumption & & & $<0.001$ \\
\hline Non & $29.1(1.6)$ & $17.7(0.5)$ & \\
\hline Mild to moderate & $50.1(1.9)$ & $58.8(0.7)$ & \\
\hline Heavy & $20.7(1.8)$ & $23.5(0.6)$ & \\
\hline Household income & & & $<0.001$ \\
\hline Q1 & $40.1(1.7)$ & $23.9(0.7)$ & \\
\hline Q2 & $27.5(1.4)$ & $25.1(0.6)$ & \\
\hline Q3 & $19.8(1.2)$ & $25.3(0.6)$ & \\
\hline Q4 & $12.6(1.3)$ & $25.7(0.8)$ & \\
\hline Educational level & & & $<0.001$ \\
\hline$\leq$ Elementary school & $39.4(2.1)$ & $15.0(0.5)$ & \\
\hline Elementary school to middle school & $9.7(0.9)$ & $9.0(0.3)$ & \\
\hline Middle school to high school & $26.2(1.7)$ & $39.2(0.6)$ & \\
\hline >University & $24.7(2.0)$ & $36.7(0.7)$ & \\
\hline Occupation (yes) & $52.9(1.9)$ & $63.2(0.5)$ & $<0.001$ \\
\hline Marital status & & & $<0.001$ \\
\hline Married & $13.0(1.1)$ & $72.0(0.6)$ & \\
\hline Unmarried & $34.9(2.5)$ & $21.0(0.5)$ & \\
\hline Others (widowed/divorced) & $52.2(2.3)$ & $6.9(0.3)$ & \\
\hline Stress (yes) & $27.7(1.3)$ & $26.2(0.5)$ & 0.294 \\
\hline Depressive mood (yes) & $20.0(1.4)$ & $11.3(0.4)$ & $<0.001$ \\
\hline Hypertension (yes) & $30.9(1.6)$ & $16.7(0.4)$ & $<0.001$ \\
\hline Diabetes mellitus (yes) & $12.4(1.0)$ & $6.6(0.2)$ & $<0.001$ \\
\hline
\end{tabular}

Values are presented as mean \pm SE or $\%(S E)$.

$\mathrm{SE}$, standard error.

${ }^{*}$ Obtained using an independent t-test for continuous variables and a chi-square test for categorical variables.
$(\mathrm{P}=0.001)$. The living alone group indicated a higher proportion of currently smoking and a lower proportion of heavy alcohol consumption than the living together group $(\mathrm{P}=0.001$ and $<0.001)$. Single-person households had lower household incomes and educational levels and were more likely to have depressive moods compared to those living together $(\mathrm{P}<0.001)$. The living alone group had a higher proportion of hypertension $(\mathrm{P}<0.001)$ and $\mathrm{DM}(\mathrm{P}<0.001)$ than the living together group. Proportions of obesity status and psychological stress were not significantly different between the groups.

Table 2 presents proportions of smoking and alcohol consumption status among individuals living alone and together by age and sex groups. Among men aged 19-39 years, the proportions of smoking and alcohol consumption statuses were not different between the living alone and living together groups. However, the proportions of currently smoking and heavy alcohol consumption were significantly higher among women aged 19-39 years living alone than those living together ( $\mathrm{P}=0.011$ and $<0.001$, respectively). As for middle-aged and elderly individuals, the living alone group demonstrated significantly higher proportions of currently smoking than the living together group both for men and women. However, there was no difference for alcohol consumption status between the groups among middle-aged and elderly men and women.

Table 3 indicates ORs (95\% CIs) of currently smoking and heavy alcohol consumption for individuals living alone compared to those living together after adjusting for confounding variables. Both in middleaged men and women, odds of currently smoking was (OR, 7.37; 95\% CI, 2.33-23.32 in men and OR, 2.36; 95\% CI, 1.04-5.36 in women) higher among individuals living alone compared to those living together, respectively.

Table 4 depicts ORs (95\% CIs) of currently smoking and heavy alcohol consumption according to socioeconomic status and chronic diseases among single-person households compared to living together groups. According to income levels, only single households with the second lowest income level had increased odds of currently smoking. As for educational level, all levels except " $\geq$ university" had higher odds of currently smoking in single-person households compared to those living together. Single-person households had greater ORs of currently smoking irrespective of occupation and hypertension status. Married single-person households had an OR of 3.57 for currently smoking (95\% CI, 1.48-8.63). Single-person households without DM, demonstrated an increased OR of 2.58 for currently smoking (95\% CI, 1.74$3.81)$.

\section{DISCUSSION}

This study examined the prevalence and odds of smoking and alcohol consumption among three different age groups of men and women according to their living arrangement. We additionally estimated ORs for these risky behaviors according to different characteristics among single-person households compared to those living together. Finally, only middle-aged (40-64 years) group in single-person households 
Table 2. Smoking and alcohol consumption status between individuals living alone and living together by age and sex groups

\begin{tabular}{|c|c|c|c|c|c|c|c|c|c|}
\hline \multirow{2}{*}{ Variable } & \multicolumn{3}{|c|}{$19-39 y$} & \multicolumn{3}{|c|}{$40-64$ y } & \multicolumn{3}{|c|}{$\geq 65 \mathrm{y}$} \\
\hline & Living alone & Living together & P-value ${ }^{\star}$ & Living alone & Living together & P-value* & Living alone & Living together & P-value* \\
\hline \multicolumn{10}{|l|}{ Men } \\
\hline Smoking status & & & 0.058 & & & $<0.001$ & & & 0.044 \\
\hline Non & $34.4(4.6)$ & $41.0(1.4)$ & & $10.2(2.1)$ & $19.7(0.9)$ & & $19.2(3.7)$ & $19.8(1.1)$ & \\
\hline Ex & $10.9(2.9)$ & $15.7(0.9)$ & & $33.5(3.7)$ & $38.1(1.0)$ & & $52.2(4.2)$ & $60.6(1.5)$ & \\
\hline Current & $54.8(5.0)$ & $43.3(1.3)$ & & $56.3(3.8)$ & $42.1(1.1)$ & & $28.6(3.4)$ & $19.6(1.3)$ & \\
\hline Alcohol consumption & & & 0.527 & & & 0.883 & & & 0.635 \\
\hline Non & $5.3(2.7)$ & $6.9(1.2)$ & & $7.4(2.9)$ & $8.4(0.9)$ & & $21.9(4.6)$ & $18.7(1.7)$ & \\
\hline Mild to moderate & $38.4(7.2)$ & $44.8(2.0)$ & & $45.4(5.9)$ & $42.7(1.6)$ & & $62.3(5.1)$ & $67.6(2.2)$ & \\
\hline Heavy & $56.3(7.5)$ & $48.3(2.1)$ & & $47.3(5.7)$ & $48.8(1.6)$ & & $15.8(3.8)$ & $13.6(1.4)$ & \\
\hline \multicolumn{10}{|l|}{ Women } \\
\hline Smoking status & & & 0.011 & & & $<0.001$ & & & $<0.001$ \\
\hline Non & $80.1(4.4)$ & $86.5(0.9)$ & & $81.9(2.5)$ & $92.9(0.5)$ & & $89.0(1.4)$ & $94.6(0.7)$ & \\
\hline Ex & 3.7 (2.2) & $6.3(0.6)$ & & $7.7(1.9)$ & $3.0(0.3)$ & & $6.2(1.1)$ & $2.4(0.5)$ & \\
\hline Current & $16.2(4.0)$ & $7.2(0.7)$ & & $10.4(1.9)$ & $4.1(0.4)$ & & $4.8(0.9)$ & $3.0(0.6)$ & \\
\hline Alcohol consumption & & & $<0.001$ & & & 0.137 & & & 0.187 \\
\hline Non & $2.3(2.3)$ & $9.7(1.0)$ & & $19.1(3.1)$ & $23.9(1.0)$ & & $54.1(2.2)$ & $48.9(1.6)$ & \\
\hline Mild to moderate & $57.3(8.4)$ & 74.6 (1.3) & & $70.4(3.7)$ & $69.1(1.1)$ & & $45.1(2.1)$ & $50.3(1.6)$ & \\
\hline Heavy & 40.4 (8.2) & $15.6(1.1)$ & & $10.5(2.3)$ & $7.0(0.6)$ & & $0.8(0.4)$ & $0.8(0.4)$ & \\
\hline
\end{tabular}

Values are presented as \% (standard error).

*P-values were obtained using a chi-square test.

Table 3. Odds ratios (95\% confidence intervals) of currently smoking and heavy alcohol consumption among individuals living alone

\begin{tabular}{|c|c|c|c|c|c|c|}
\hline \multirow{2}{*}{ Variable } & \multicolumn{2}{|c|}{$19-39 y$} & \multicolumn{2}{|c|}{$40-64$ y } & \multicolumn{2}{|c|}{$\geq 65 y$} \\
\hline & Living together & Living alone & Living together & Living alone & Living together & Living alone \\
\hline \multicolumn{7}{|l|}{ Total } \\
\hline Currently smoking & 1 & $2.38(1.12-5.05)$ & 1 & $3.95(2.33-6.69)$ & 1 & $1.62(0.90-2.91)$ \\
\hline Heavy alcohol consumption & 1 & $1.62(0.39-6.68)$ & 1 & $1.64(0.72-3.73)$ & 1 & $0.67(0.29-1.52)$ \\
\hline \multicolumn{7}{|l|}{ Men } \\
\hline Currently smoking & 1 & $2.29(0.80-6.54)$ & 1 & 7.37 (2.33-23.32) & 1 & $1.41(0.49-4.05)$ \\
\hline Heavy alcohol consumption & 1 & $1.01(0.19-5.29)$ & 1 & $1.60(0.21-12.31)$ & 1 & $0.56(0.21-1.46)$ \\
\hline \multicolumn{7}{|l|}{ Women } \\
\hline Currently smoking & 1 & $3.19(0.99-10.34)$ & 1 & $2.36(1.04-5.36)$ & 1 & $1.44(0.72-2.91)$ \\
\hline Heavy alcohol consumption & 1 & $3.49(0.30-41.04)$ & 1 & $1.63(0.63-4.22)$ & 1 & $0.60(0.05-7.88)$ \\
\hline
\end{tabular}

Odds ratios (95\% confidence intervals) were calculated by using multivariable logistic regression analysis, while adjusting for age, sex, body mass index, smoking status, alcohol consumption, income, educational level, occupation, psychological stress, depressive mood, hypertension, and diabetes mellitus.

was associated with higher odds for currently smoking. However, heavy alcohol consumption was not significantly associated with living alone in all age and sex groups. Our findings suggest that supports especially for middle-aged single-person households may be important in controlling risky health behaviors such as smoking.

Several previous studies have reported associations between living arrangements and health behaviors while producing conflicting findings. ${ }^{7-14)}$ Previous research assessed smoking and alcohol consumption status between living with a partner and living without a partner. A Korean study found a higher odds of smoking (OR, 2.27; 95\% CI, 1.09-4.73) and alcohol consumption (OR, 5.33; 95\% CI, 1.65-17.24) among middle-aged adults living without a partner. ${ }^{9}$ Health behaviors and illness were significantly worse in middle-aged Koreans living without their spouses. ${ }^{10)}$ Our study's results are in line with these previous studies, especially in for the middle-aged population. Single-per- son households have been highlighted as a vulnerable health group. ${ }^{10,14,15)}$ Our findings imply a prevalent poor health status related to smoking in single-person households.

Meanwhile, a study of elderly individuals found that the odds of smoking was 1.80 times (95\% CI, 1.21-2.67) higher for men living alone and 1.41 times (95\% CI, 1.03-1.92) higher for women living alone; however, alcohol consumption was not associated with living alone or together. ${ }^{11)}$ A Chinese study has also reported the importance of living arrangements with respect to smoking and alcohol consumption in the elderly. Conversely, we found that more single-person households of $\geq 65$ years are current smoker but the odds of currently smoking was not significant in these age group. These findings might have been associated with familial influence. A previous study showed that living with family has an influence on health behaviors through direct and indirect social control. Direct social control implies changing healthy 
Table 4. Odds ratio (95\% confidence interval) of currently smoking and heavy alcohol consumption according to socioeconomic status and chronic diseases among singleperson households

\begin{tabular}{|c|c|c|c|c|}
\hline \multirow{2}{*}{ Variable } & \multicolumn{2}{|c|}{ Currently smoking } & \multicolumn{2}{|c|}{ Heavy alcohol consumption } \\
\hline & Living together & Living alone & Living together & Living alone \\
\hline \multicolumn{5}{|l|}{ Household income } \\
\hline Q1 & 1 & $1.51(0.90-2.53)$ & 1 & $1.20(0.64-2.25)$ \\
\hline Q2 & 1 & $3.91(2.14-7.14)$ & 1 & $0.56(0.21-1.48)$ \\
\hline Q3 & 1 & $2.08(0.69-6.23)$ & 1 & $0.74(0.24-2.32)$ \\
\hline Q4 & 1 & $2.94(0.99-8.72)$ & 1 & $1.89(0.62-5.79)$ \\
\hline \multicolumn{5}{|l|}{ Education level } \\
\hline$\leq$ Elementary school & 1 & $2.34(1.33-4.11)$ & 1 & $0.93(0.47-1.86)$ \\
\hline Elementary school to middle school & 1 & $4.21(1.52-11.63)$ & 1 & $0.82(0.30-2.25)$ \\
\hline Middle school to high school & 1 & $3.20(1.64-6.23)$ & 1 & $0.54(0.23-1.29)$ \\
\hline zUniversity & 1 & $2.24(0.90-5.59)$ & 1 & $3.12(0.79-12.39)$ \\
\hline \multicolumn{5}{|l|}{ Occupation (yes) } \\
\hline No & 1 & $1.68(1.07-2.63)$ & 1 & $1.23(0.70-2.17)$ \\
\hline Yes & 1 & $3.12(1.79-5.45)$ & 1 & $1.01(0.51-2.01)$ \\
\hline \multicolumn{5}{|l|}{ Marital status } \\
\hline Married & 1 & $3.57(1.48-8.63)$ & 1 & $0.92(0.35-2.45)$ \\
\hline Unmarried & 1 & $1.52(0.69-3.37)$ & 1 & $1.90(0.52-7.03)$ \\
\hline Others (widowed/divorced) & 1 & $0.86(0.50-1.46)$ & 1 & $1.33(0.58-3.04)$ \\
\hline \multicolumn{5}{|l|}{ Hypertension } \\
\hline No & 1 & $2.25(1.47-3.44)$ & 1 & $1.10(0.64-1.90)$ \\
\hline Yes & 1 & $3.56(1.66-7.64)$ & 1 & $0.57(0.23-1.44)$ \\
\hline \multicolumn{5}{|l|}{ Diabetes mellitus } \\
\hline No & 1 & $2.58(1.74-3.81)$ & 1 & $0.90(0.55-1.48)$ \\
\hline Yes & 1 & $3.02(0.98-9.33)$ & 1 & $1.50(0.60-3.74)$ \\
\hline
\end{tabular}

Odds ratios (95\% confidence intervals) were calculated by using multivariable logistic regression analysis while adjusting for age, sex, body mass index, smoking status, alcohol consumption, income, educational level, occupation, psychological stress, depressive mood, hypertension, and diabetes mellitus.

habits as a result of persuasion and requests from people around, and indirect social control implies trying to develop healthier habits because of a responsibility toward the family. ${ }^{8,16)}$ On the other hand, elderly people have fewer parental responsibilities and duties than younger parents. This may explain the different findings in the association between living arrangements and currently smoking according to age groups.

The present study did not indicate any significant associations between heavy alcohol consumption and living alone. Chung et al. ${ }^{17)}$ investigated why men have a greater high-risk alcohol drinking (HRD)tendency than women in South Korea. They found that that the gap of HRD between men and women accounted for $96 \%$ of the gender difference, whereas gender differences in socio-economic characteristics explained just $4 \%$ of the difference. ${ }^{17)}$ Another study about alcohol consumption suggested different risk factors between China and Norway. Factors such as younger age, higher level of education, living in urban areas, living with a spouse or partner, and better health status were related to higher likelihood of alcohol consumption among Norwegian older women and men, while better health status and poorer life satisfaction were related to higher likelihood of alcohol consumption among the Chinese. ${ }^{18)}$ Therefore, cultural background and national economic differences in the research environment may affect findings from studies in different regions.

This study has several limitations. First, we could not determine a causal relationship between living alone and smoking and alcohol consumption status owing to the cross-sectional design. Second, smoking and alcohol consumption based on the self-reported questionnaire may be under-reported leading to a recall bias. Third, we could not assess the duration of living alone due to lack of data from KNHANES. Fourth, we could not consider all confounding factors completely as mentioned above. Despite the limitations, the major strengths of our study are as follows. We used a nationally representative database and produced nationwide representative estimates regarding living alone and smoking and alcohol consumption. Furthermore, we performed a comprehensive adjustment for potential confounding variables and various subgroup analyses according to combinations of age and sex and found that middle-aged men and women living alone tend to have unhealthy behaviors such as currently smoking.

In conclusion, from this population-based study, we found that living alone is associated with increased odds of currently smoking, especially in middle-aged people even after adjusting for potentially confounding factors. Our study findings suggest that living alone is an independent associated factor for currently smoking in middle-aged people. Public health concerns seem to be needed for middle-aged single-person households to prevent health risks related to smoking. 


\section{CONFLICT OF INTEREST}

No potential conflict of interest relevant to this article was reported.

\section{ORCID}

Byoungduck Han: https://orcid.org/0000-0003-2830-1174

Sung Jung Cho: https://orcid.org/0000-0002-3156-5931

Seung Jin Jung: https://orcid.org/0000-0001-8821-0050

Youn Huh: https://orcid.org/0000-0001-8899-9637

Ga Eun Nam: https://orcid.org/0000-0002-6739-9904

\section{REFERENCES}

1. Korea Institute for Health and Social Affairs. Policy implications of changes in family structure: focused on the increase of single person households in Korea. Sejong: Korea Institute for Health and Social Affairs; 2012.

2. Statistics Korea. Household projections 2010-2035 [Internet]. Daejeon: Statistics Korea; c2012 [cited 2018 Jun 1]. Available from: http://kostat. go.kr/portal/korea/kor_nw/2/2/6/index.board?bmode=read\&bSeq= \&aSeq=255176\&pageNo=1\&rowNum=10\&navCount=10\&currPg=\&sT arget $=$ title \&sTxt $=\backslash$.

3. Kim JB. The study of moderating effects upon gender differences in attitudes toward marriage. J Soc Sci 2013;39:1-24.

4. Kang YJ. Study on non-marriage types and related factors among young unmarried adults: focus on socio-demographic characteristics and family values. Korean J Community Living Sci 2017;28:241-56.

5. Lee YB. One-person households and their policy implications. Health Welf Forum 2017;(252):64-77.

6. World Health Organization. Constitution of the World Health Organization. In: World Health Organization, editor. Handbook of basic documents. 5th ed. Geneva: World Health Organization; 1952. p. 3-20.

7. Kim A, Park NL, Lee JA, Park H. Health behaviors and mental health of Korean young adults from single households: data analysis from the 5th Korea National Health and Nutrition Examination Survey (20102012). Korean J Fam Pract 2017;7:667-73.

8. Jeong S, Cho SI. Effects of living alone versus with others and of housemate type on smoking, drinking, dietary habits, and physical activity among elderly people. Epidemiol Health 2017;39:e2017034.

9. Yim HJ, Park HA, Kang JH, Kim KW, Cho YG, Hur YI, et al. Marital status and health behavior in middle-aged Korean adults. Korean J Fam Med 2012;33:390-7.

10. Kim A, Lee JA, Park HS. Health behaviors and illness according to marital status in middle-aged Koreans. J Public Health (Oxf) 2018;40:e99-106.

11. Kim JG. The impact of family type on health behavior of elderly people. J Welf Aged 2011;51:35-56.

12. Zhang J, Wu L. Cigarette smoking and alcohol consumption among Chinese older adults: do living arrangements matter? Int J Environ Res Public Health 2015;12:2411-36.

13. Tani Y, Kondo N, Takagi D, Saito M, Hikichi H, Ojima T, et al. Combined effects of eating alone and living alone on unhealthy dietary behaviors, obesity and underweight in older Japanese adults: results of the JAGES. Appetite 2015;95:1-8.

14. Davis MA, Moritz DJ, Neuhaus JM, Barclay JD, Gee L. Living arrangements, changes in living arrangements, and survival among community dwelling older adults. Am J Public Health 1997;87:371-7.

15. Nielsen KM, Faergeman O, Larsen ML, Foldspang A. Danish singles have a twofold risk of acute coronary syndrome: data from a cohort of 138290 persons. J Epidemiol Community Health 2006;60:721-8.

16. Umberson D. Family status and health behaviors: social control as a dimension of social integration. J Health Soc Behav 1987;28:306-19.

17. Chung W, Lim S, Lee S. Why is high-risk drinking more prevalent among men than women?: evidence from South Korea. BMC Public Health 2012;12:101.

18. Li J, Wu B, Selbæk G, Krokstad S, Helvik AS. Factors associated with consumption of alcohol in older adults - a comparison between two cultures, China and Norway: the CLHLS and the HUNT-study. BMC Geriatr 2017;17:172. 